\title{
Clinical and pathological effects of different acrylic intracorneal ring segments in corneal additive surgery
}

\author{
P. Pérez-Merino a , F. Parra ${ }^{\text {b }}$, L. Ibares-Frías ${ }^{a}$, P. Gallego a , B. Vázquez-Lasa ${ }^{\text {b,*, L. Benito }}{ }^{\text {, }}$, J. San Román ${ }^{\text {b }}$, \\ C. Martínez-García ${ }^{\mathrm{c}}$, J. Merayo-Lloves ${ }^{\mathrm{a}}$ \\ ${ }^{a}$ Instituto Universitario de Oftalmobiología Aplicada (IOBA), University of Valladolid, C/Ramón y Cajal 7, 47005 Valladolid, Spain \\ ${ }^{\mathrm{b}}$ Institute of Polymer Science and Technology, CSIC, C/Juan de la Cierva 3, 28006 Madrid, Spain \\ ${ }^{\mathrm{c}}$ Departamento de Biología Celular, Faculty of Medicine, University of Valladolid, C/Ramón y Cajal 7, 47005 Valladolid, Spain
}

\section{A R T I C L E I N F O}

\section{Article history:}

Received 4 August 2009

Received in revised form 17 December 2009

Accepted 11 January 2010

Available online 18 January 2010

\section{Keywords:}

Acrylics

Polymethylmethacrylate

Keratoprothesis

Cornea

Biocompatibility

\begin{abstract}
A B S T R A C T
The objective of this work was to evaluate the potential use of less stiff materials based on acrylic copolymers of methyl methacrylate/2-ethylhexyl acrylate (MMA/EHA) as devices to correct, stabilize and improve the effect of poly(methyl methacrylate) (PMMA) intracorneal ring segments. MMA/EHA and PMMA intracorneal ring segments were surgically implanted in the corneas of Lohmann Classic hens. The effects of the intracorneal ring segments were assessed by optical measurements and corneal tolerance was evaluated through biomicroscopic examination over a 90-day observation period and by conventional histology. The experimental results demonstrated that the intracorneal ring segments made of MMA/EHA copolymers provided a significant change in the corneal curvature and an improved in vivo response compared to those obtained for PMMA rings, which was attributed to the higher flexibility of the copolymeric materials, indicating that these systems might be considered suitable as an alternative to those currently used, for application in clinical practice.
\end{abstract}

(c) 2010 Acta Materialia Inc. Published by Elsevier Ltd. All rights reserved.

\section{Introduction}

Corneal ectatic diseases include a group of corneal disorders characterized by a progressive corneal thinning and steepening with irregular increase in the corneal refractive power. Keratoconus is the most common corneal ectatic disease, although progressive structural corneal deformation similar to keratoconus may also occur surgically induced after laser in situ keratomileusis (LASIK) $[1,2]$. At present, there are several options to treat corneal ectatic diseases before a corneal transplant. A surgical alternative method to stabilize or delay the progression of the ectatic disease involves the implantation of intracorneal ring segments [3-5]. According to the postulates of Barraquer [6] and Blavatskaya [7], the intracorneal ring segments implanted in the corneal stroma lead to a flattening on the corneal surface. Furthermore, the intracorneal ring segments tend to preserve corneal asphericity with obvious contribution to better visual outcome $[8,9]$ and also, this surgery presents the advantage of reshaping the cornea without removing tissue and maintaining untouched the central cornea.

Currently, there are three models of intracorneal ring segments with different technical specification: Intacs prescription inserts (Addition Technologies, Inc., Fremont, CA, USA); intracorneal ring

\footnotetext{
* Corresponding author. Tel.: +34 91 5618806; fax: +34 915644853

E-mail address: bvazquez@ictp.csic.es (B. Vázquez-Lasa).
}

segments originally designed by Paulo Ferrara, Ferrara Ring Segment (Ferrara e Hijos SL, Valladolid, Spain) and Keraring (Mediphacos Inc., Belo Horizonte, Brazil); and Bisantis segments (Opticon 2000 SpA and Soleko SpA, Rome, Italy). These types are made from poly(methyl methacrylate) (PMMA). Previous studies reported the good optical and mechanical properties of PMMA segments, with acceptable biocompatibility and clinical tolerance [10,11]. However, this is a rigid and hard material that differs from the composition of the cornea; it shows different clinical and histological complications and its stability is difficult to predict [12,13]. Several studies of PMMA intracorneal rings described an extracellular intrastromal deposit in the lamellar channel around the implant [14] and a decrease of the keratocyte density anterior to the implant [15] as common clinical and histological findings respectively. Therefore, in this paper we assessed the potential use of hydrophobic acrylic copolymers as a new material for intracorneal rings based on the fact that these copolymers present a high longterm biostability and might be more biocompatible than PMMA, and it has been verified that the flexibility of the macromolecular chains could be precisely controlled. The substitution of PMMA by another more flexible material will bring benefits regarding the in vivo response of these intracorneal rings. Likewise, the orthopedic function of these segments might be extended.

The aim of the present study was to evaluate the outcome and the potential role of implanting methyl methacrylate/2-ethylhexyl 
acrylate (MMA/EHA) copolymers as an implant to correct, stabilize and improve the effect of PMMA intracorneal rings.

\section{Materials and methods}

\subsection{Materials}

The monomers methyl methacrylate (MMA) and 2-ethylhexyl acrylate (EHA) were purchased from Sigma-Aldrich and used after successive extractions with aqueous $\mathrm{NaOH}$ solution (5\%) and distilled water. Azobisisobutyronitrile (AIBN) (Merck) was recrystallized from methanol (m.p. $104^{\circ} \mathrm{C}$ ). Thermanox ${ }^{\circledR}$ (TMX) control discs (Labclinics S.L.) and fetal bovine serum (FBS) (Gibco) were used as received for in vitro and biological assays. Tissue culture media, additives, trypsin, and 3-(4,5-dimethylthiazol-2-yl)-2,5diphenyltetrazolium bromide (MTT) were all purchased from Sigma.

\subsection{Preparation and characterization of MMA/EHA copolymers}

High conversion copolymers from monomer MMA/EHA feed compositions of 95:5, 90:10 and 85:15 wt.\% were obtained by bulk radical polymerization using AIBN ( $0.5 \mathrm{wt}$.\% with respect to monomers) as a free radical initiator. $1 \mathrm{ml}$ of the monomer mixture was introduced in Teflon cylinder moulds of $19 \mathrm{~mm}$ of diameter to obtain discs of $3 \mathrm{~mm}$ thickness. The reaction medium was saturated with $\mathrm{N}_{2}$ atmosphere for $15 \mathrm{~min}$ and then the tube was capped and heated at $60{ }^{\circ} \mathrm{C}$. The reaction was allowed to proceed for $46 \mathrm{~h}$. The polymerized samples were extracted from the moulds and submitted to a post-curing at $70{ }^{\circ} \mathrm{C}$ for $48 \mathrm{~h}$ to complete polymerization. PMMA samples were obtained under the same reaction conditions and tested as control.

Copolymer composition and residual monomer content were determined from the proton nuclear magnetic resonance $\left({ }^{1} \mathrm{H}\right.$ NMR) spectra obtained in an INOVA-300 spectrophotometer. The spectra were recorded in deuterated chloroform $(10 \mathrm{w} / \mathrm{v})$ at $25^{\circ} \mathrm{C}$. Tetramethylsilane (TMS) was used as internal standard. Refractive index was measured with an Abbe refractometer (ZEISS 133988 ) at $589 \mathrm{~nm}$ (line D from sodium lamp). Measures were taken from wet specimens. Glass transition temperatures $\left(T_{\mathrm{g}}\right)$ were measured by differential scanning calorimetry (DSC) with a Perkin Elmer DSC7 interfaced to a thermal analysis data system TAC 7/DX. The dry samples $(15-20 \mathrm{mg}$ ) were placed in aluminium pans and heated from -20 to $150{ }^{\circ} \mathrm{C}$ at a constant rate of $20^{\circ} \mathrm{C} \mathrm{min}^{-1} . T_{\mathrm{g}}$ was taken as the midpoint of the heat capacity transition. A Vickers indentor attached to a Leitz microhardness tester was used to carry out microindentation measurements. Experiments were undertaken at room temperature. A contact load of $0.98 \mathrm{~N}$ and a contact time of $25 \mathrm{~s}$ were used. Microhardness $\left(H_{\mathrm{v}}\right)$ values were calculated according to the following relationship:

$H_{\mathrm{v}}=1.854 \times p / d^{2}(\mathrm{MPa})$

where $p$ is the contact load $(\mathrm{N})$, and $d$ is the diagonal length of the projected indentation area $\left(\mathrm{mm}^{2}\right)$.

Swelling of copolymers was attained from discs $(19 \mathrm{~mm}$ in diameter and $3 \mathrm{~mm}$ thickness) conditioned in phosphate buffered solution (PBS) ( $\mathrm{pH} 7.4)$ at $37^{\circ} \mathrm{C}$ until they reached equilibrium. Hydration degree $(H \%)$ was calculated as the percentage of the relationship between the weight of water uptake at equilibrium and the initial weight of the dry disc. In all the experiments a minimum of three samples was measured and averaged. Static contact angles were measured on copolymer surface discs by using a contact angle measuring system G10 (Krüss) by the sessile drop technique and employing liquids with known surface tension: water, $\gamma_{1}=72.8 \mathrm{mN} \mathrm{m}^{-2}$ and methylene iodide, $\gamma_{1}=51.8 \mathrm{mN} \mathrm{m}^{-2}$, where $\gamma_{1}$ refers to the total surface free energy of the liquid. A minimum of 10 drops were applied on each sample. The surface free energy of the copolymers $\left(\gamma_{s}\right)$ was calculated by the Fowkes [16] and Owens [17] method according to the following equations:

$$
\begin{aligned}
& \gamma_{s}=\gamma_{s}^{d}+\gamma_{s}^{p} \\
& (1+\cos \theta) \gamma_{1} / 2=\left(\gamma_{s}^{d} \gamma_{l}^{d}\right)^{1 / 2}+\left(\gamma_{s}^{p} \gamma_{l}^{p}\right)^{1 / 2}
\end{aligned}
$$

where $\theta$ is the contact angle, $\gamma_{s}$ and $\gamma_{1}$ are the surface free energy of solid and liquid respectively and $\gamma_{s}^{d}, \gamma_{s}^{p}, \gamma_{l}^{d}$ and $\gamma_{l}^{p}$ are the dispersive and polar components of solid and liquid respectively. The results obtained from micro hardness and swelling experiments were analysed with the use of one-way analysis of variance (ANOVA) at a significance level of $p<0.05$.

\subsection{In vitro biocompatibility}

\subsubsection{Cell culture conditions}

The biological response to the materials was tested with human fibroblasts. The culture medium was Dulbecco's modified Eagle's medium enriched with $4500 \mathrm{mg} \mathrm{l}^{-1}$ of glucose (DMEM, Sigma) supplemented with $10 \%$ foetal bovine serum, $200 \mathrm{mM}$ L-glutamine, 100 units $\mathrm{ml}^{-1}$ penicillin and $100 \mu \mathrm{g} \mathrm{ml}^{-1}$ streptomycin, modified with HEPES. The culture medium was changed at selected time intervals with care to cause little disturbance to culture conditions. Thermanox $^{\circledR}$ (TMX) was used as a negative control and a $1 \% \mathrm{v} / \mathrm{v}$ Triton $\mathrm{X}-100$ solution in culture medium was used as a positive control. Discs of the copolymers of $14 \mathrm{~mm}$ diameter and $3 \mathrm{~mm}$ thickness were used. All specimens were UV sterilized for $2 \mathrm{~h}$ on each side.

\subsubsection{MTT assay}

Discs of copolymers and TMX were set up in $5 \mathrm{ml}$ of DMEM. They were placed on a roller mixer at $37{ }^{\circ} \mathrm{C}$ and the medium was removed at different time periods ( $6 \mathrm{~h}, 1,2,3$ and 7 days) and replaced with another $5 \mathrm{ml}$ of fresh medium. All the extracts were obtained under sterile conditions. Cells were seeded at a density of $8 \times 10^{4}$ cells $\mathrm{ml}^{-1}$ in complete medium in a sterile 96 -well culture plate and incubated to confluency. After $24 \mathrm{~h}$ of incubation the medium was replaced with the corresponding extracts. Also a Triton X-100 solution of $1 \% \mathrm{v} / \mathrm{v}$ in culture medium, used as a positive control, was prepared. After that, plates were incubated at $37{ }^{\circ} \mathrm{C}$ in humidified air with $5 \% \mathrm{CO}_{2}$ for $24 \mathrm{~h}$. A solution of MTT was prepared in warm PBS $\left(0.5 \mathrm{mg} \mathrm{ml}^{-1}\right)$ and the plates were incubated at $37^{\circ} \mathrm{C}$ for $4 \mathrm{~h}$. Excess medium and MTT were removed and DMSO was added to all wells in order to dissolve the MTT taken up by the cells. This was mixed for $10 \mathrm{~min}$ and the absorbance was measured with a Biotek ELX808IU detector using a test wavelength of $570 \mathrm{~nm}$ and a reference wavelength of $630 \mathrm{~nm}$. The cell viability was calculated from equation:

Relative cell viability $=100 \times\left(O D_{\mathrm{S}}-O D_{\mathrm{B}}\right) /\left(O D_{\mathrm{C}}-O D_{\mathrm{B}}\right)$

where $O D_{\mathrm{S}}, O D_{\mathrm{B}}$ and $O D_{\mathrm{C}}$ are the optical density of formazan production for the sample, blank (DMEM without cells) and control (TMX), respectively. Analysis of variance (ANOVA) of the results for copolymers was performed with respect to TMX at $p<0.05$ of significance level.

\subsection{In vivo biocompatibility}

\subsubsection{Animals}

Twenty Iber Braun adult hens, Gallus gallus domesticus (weight $2 \mathrm{~kg}$ ) were used. Animals were cared for following the guidelines of the Association for Research in Vision and Ophthalmology (ARVO) Statement for the Use of Animals in Ophthalmic and Vision Research. The hens were anaesthetized with an intramuscular 
injection of ketamine hydrochloride $\left(37.5 \mathrm{mg} \mathrm{kg}^{-1}\right.$; Ketolar, ParkeDavis, SA, Barcelona, Spain) and xylazine hydrochloride (5 mg kg-1; Rompun, Bayer, AG, Leverkusen, Germany) followed by topical application of $0.5 \%$ tetracaine chlohydrate and $1 \mathrm{mg}$ of oxybuprocaine (Colircusí Anestésico Doble, Alconcusí, SA, Barcelona, Spain). Intracorneal rings implantation was performed in both eyes (PMMA $n=16$, MMA/EHA 95:5 $n=12$, MMA/EHA 90:10 $n=12$ ). At 30 and 90 days animals were euthanized by an overdose of pentobarbital while the animal was under general anesthesia.

\subsubsection{Intracorneal rings}

Ferrara ring segments made of PMMA were used as control. Copolymers of MMA/EHA in two molar ratios 95:5 and 90:10 were tested in these experiments. All intracorneal ring segments (PMMA and MMA/EHA copolymers) had the same shape and size: triangular cross-section, $0.15 \mathrm{~mm}$ of thickness, arc length of $90^{\circ}$, inner diameter of $4.4 \mathrm{~mm}$ and outer diameter of $5.6 \mathrm{~mm}$.

\subsubsection{Surgical procedure}

The surgical planning was made according to the mechanical method provided by Ferrara [18]. The surgical procedure was carried out under general anesthesia. All the operations were performed by an experienced surgeon (L.I.F.). A circular Ferrara marker, previously dyed in sterile gentian violet pen, centred where the microscopy light is reflected on the cornea, was used to create three concentric circles on the cornea of 3,5 and $7 \mathrm{~mm}$. The corneal thickness was measured at the incision site with ultrasonic pachymetry (Sonogage, Cleveland, OH, USA). Using an adjustable Ferrara diamond blade knife the incision was created nasally on the horizontal meridian, between the 5 and 7 marked circles, at $80 \%$ of the corneal thickness. Then, a corneal bag was made using the Suarez spreader to facilitate the beginning of the tunnel preparation. The Ferrara spatula, modified for the hen cornea (diameter $5 \mathrm{~mm}$ ), was inserted in the bag and a circular tunnel was formed in the stroma in the clockwise direction. The PMMA and MMA-EHA segments were implanted into the tunnel, maintaining a distance from the incision of approximately $1 \mathrm{~mm}$. In this study only one segment was implanted in each eye.

\subsubsection{Clinical course}

Biomicroscopic examinations of the cornea and the anterior segment were performed in all eyes before and after intracorneal rings implantation with a surgical microscope (Takagi OM-5, Nakano, Japan). To evaluate complications such as edema, haze and deposits the animals were observed at 7, 14, 30, 60 and 90 days after surgery. Corneal thickness was assessed with ultrasound pachymetry (Sonogage, Cleveland, OH, USA).

\subsubsection{Optical measurements: keratometry and refractive state}

The effects of the intracorneal ring treatment were assessed by measurements of corneal curvature and refractive state. Measurements of the corneal radius of curvature were obtained using a custom-built infrared photokeratometer as previously described [19]. The measurements were performed as described by Garcia de la Cera [20]. Corneal curvature was expressed as dioptric power using the value of 1.373 for the refractive index of the cornea [21]. Measurements of the peripheral radii of curvature were also attempted; however the bad quality of the reflections prevented us from obtaining consistent results. The refractive state was evaluated with an automated eccentric infrared photorefractor [19]. The most hyperopic value at which the retinal reflex was reversed was taken to be the resting refraction [22]. Post-operative corneal curvature and refractive state measurements were taken at 30 and 90 days. Measurements were done with the animals awake and under natural viewing conditions.

\subsubsection{Biophysics measurements: direct transmittance}

Direct transmittance is the measurement of light that the cornea allows to pass through it in the same direction. These measurements were taken by a device developed by our group [23] immediately after euthanasia at 30 and 90 days. The magnitude of direct transmittance for red wavelength $(R=632.8 \mathrm{~nm})$ was analysed.

\subsubsection{Tissue processing and light microscopy}

The processed corneas were fixed with buffered $10 \%$ formalin for $24 \mathrm{~h}$, washed in $0.1 \mathrm{M}$ phosphate buffered solution and embedded in paraffin wax. The eyes were processed at the same times. Sections were stained with hematoxylin-eosin (H-E). The sections were examined under an Axiophot light microscope (Zeiss, Oberkochen, Germany) and microphotographs were obtained with a SPOT digital camera (Diagnostic Instruments, Sterling Heights, MI, USA).

\subsubsection{Immunofluorescence}

An anti $\alpha$-smooth muscle actin ( $\alpha$-SMA) monoclonal antibody (Dako Corp., Carpinteria, CA, USA) was used to detect myofibroblasts, and a secondary antibody Texas red goat antimouse IgG (Molecular Probes) was also utilized. Nuclei were stained with DAPI (Molecular Probes). Sections were examined under an Axiophot fluorescence incorporated microscope (Zeiss, Oberkochen, Germany) and photomicrographs were captured with the SPOT digital camera (Diagnostic Instruments, Sterling Heights, MI, USA).

\subsubsection{Statistical analysis}

A comparison of confidence intervals was used to determine the statistical significance of change between time points. The differences in keratometric and refractive values were evaluated by comparing confidence intervals (95\%). Results are presented as mean \pm standard deviation. The level of statistical significance was set at $p<0.05$.

\section{Results}

\subsection{Preparation of copolymeric systems}

Three different MMA/EHA copolymers corresponding to feed compositions of 5, 10 and 15 wt.\% of EHA respectively, were obtained by high conversion copolymerization reaction. Copolymer composition was analysed by the corresponding ${ }^{1} \mathrm{H}$ NMR spectra. The integrated intensity of the signal assigned to $-\mathrm{OCH}_{2}-(3.64 \delta)$ protons of the 2-ethylhexyl acrylate unit was compared with that of the signal at $3.55 \delta$ ascribed to the $-\mathrm{OCH}_{3}-$ protons of the methyl methacrylate unit. In all cases the copolymer composition approached that of the monomer feed as expected for high conversion reactions (see Table 1 ). Residual monomer content was also determined from the ${ }^{1} \mathrm{H}$ NMR spectra considering both monomeric species. The signals at $6.38 \delta$ ascribed to $\mathrm{CH}_{2}=\mathrm{CH}$ protons of EHA and at $5.55 \delta$ ascribed to the $\mathrm{CH}_{2}=\mathrm{C}$ protons of MMA were compared with copolymeric signals at $3.64 \delta$ of EHA unit and $3.55 \delta$ of MMA unit. Values of residual monomer were around $1 \mathrm{wt} . \%$ in all cases. Optical, thermal and mechanical properties of the copolymeric materials were also analysed along with those of pristine PMMA obtained under the same reaction conditions (Table 1). Optical properties of copolymers remained unaltered with respect to PMMA for amounts of EHA lower than $10 \mathrm{wt} . \%$, and a slight decrease in the refractive index was observed for a higher acrylate content. Glass transition temperature decreased linearly $(R=0.994)$ with the content of EHA, reaching values close to $70{ }^{\circ} \mathrm{C}$ for the copolymer with the highest EHA content. Accordingly, microhardness of copolymeric materials decreased linearly 
Table 1

Values of copolymer composition, residual monomer content, refractive indexes, glass transition temperature, and hardness of MMA/EHA copolymer materials.

\begin{tabular}{|c|c|c|c|c|c|c|c|}
\hline \multirow[t]{2}{*}{ Feed composition (wt.\%) } & \multicolumn{2}{|c|}{ Copolymer composition (wt.\%) } & \multicolumn{2}{|c|}{ Residual monomer content (wt.\%) } & \multirow[t]{2}{*}{$n_{\mathrm{D}}^{20}$} & \multirow[t]{2}{*}{$T_{\mathrm{g}}\left({ }^{\circ} \mathrm{C}\right)$} & \multirow[t]{2}{*}{$H_{\mathrm{v}}(\mathrm{MPa})$} \\
\hline & MMA & EHA & MMA & EHA & & & \\
\hline PMMA & 100 & - & $1.0 \pm 0.03$ & - & 1.4870 & 108 & $129.5 \pm 1.03$ \\
\hline MMA/EHA 95:5 & $94.6 \pm 1.1$ & $5.4 \pm 1.0$ & $0.6 \pm 0.02$ & $0.3 \pm 0.08$ & 1.4865 & 99 & $122.6 \pm 1.82$ \\
\hline MMA/EHA 90:10 & $89.9 \pm 1.2$ & $10.1 \pm 1.2$ & $0.6 \pm 0.07$ & $0.2 \pm 0.03$ & 1.4840 & 82 & $98.4 \pm 1.26$ \\
\hline MMA/EHA 85:15 & $86.0 \pm 0.9$ & $14.0 \pm 1.0$ & $0.7 \pm 0.00$ & $0.3 \pm 0.04$ & 1.4210 & 71 & $80.6 \pm 1.02$ \\
\hline
\end{tabular}

( $R=0.990)$ with the acrylate content. All the copolymers presented a significantly lower microhardness compared to PMMA, presenting a value close to $80 \mathrm{MPa}$ for the copolymer richest in the acrylate. For comparison purposes, dehydrated corneas of gallus domesticus was also measured giving a value of $101.3 \pm 1.55$ which was not significantly different from that presented by the MMA/ EHA $90 / 10$ copolymer $(98.4 \pm 1.26)$. Wettability was studied through water sorption and surface properties. Results are shown in Table 2. Hydration degree slightly decreased with the content of EHA in the copolymer. No significant differences were found between water content of the copolymer containing 5 wt.\% EHA compared to that of PMMA, but water content was statistically lower for copolymers having higher amounts of EHA. Water contact angle of copolymers increased with the amount of acrylate and consequently, surface energy of solid $\left(\gamma_{\mathrm{s}}\right)$ showed the opposite trend; however, the change was considered negligible for contents lower than $10 \mathrm{wt}$ \% EHA and it became more apparent for the copolymer richest in EHA, in which the decrease of $\gamma_{s}$ was mainly at expense of that of the polar component.

\subsection{In vitro biocompatibility}

MTT results manifested absence of cytotoxicity due to lixiviates or extracts of the different copolymer discs, indicating that the materials did not release any harmful substance for the cells. Results of the high cellular viability measured in the presence of the corresponding lixiviates are presented in Fig. 1.

\subsection{In vivo biocompatibility}

The Ferrara ring segments are made of PMMA and are characterized by a triangular cross-section that induces a prismatic effect on the cornea. Intracorneal segments of MMA/EHA copolymers prepared with feeds of 95:5 and 90:10 were performed using the same design as those of commercial Ferrara segments, by applying micro mechanized techniques. PMMA Ferrara intracorneal segments were also implanted and analysed for comparison purposes.

\subsubsection{Clinical evaluation}

All intracorneal segments were successfully implanted in all eyes. No surgical complications such as anterior chamber perforation or superficial implantation occurred. No further complications such as extrusion or migration were observed. After intracorneal rings implantation light corneal stromal edema around the incision site and the stromal channel, where the segments were placed, was observed between 7 and 14 days postoperatively, which subsided spontaneously over time in both groups, PMMA and MMA/EHA (95:5 and 90:10). Also, at 14 days the corneal thickness recovered its normal value. Corneal haze was observed around the incision site and the stromal channel in the first 30 days post-operative (grade $0-1$ in Fantes's scale) and it decreased at 90 days in both groups. Approximately after 14 days, peri-annelar deposits appeared around the segments. The intrastromal deposits, which were small and opaque deposits, were observed at the edges of the ring. These deposits remained visible over time (Fig. 2). No significant differences in the clinical evaluation between PMMA and the MMA/EHA (95:5 and 90:10) copolymers were found throughout the follow-up.

\subsubsection{Corneal radius of curvature and refractive error}

Quantitative changes in corneal radius of curvature are presented in Table 3. The mean values of corneal radius showed a significant decrease with time in all groups, indicating that the central corneal curvatures were significantly flattened after 90 days as compared to the preoperative values. Keratometric preoperative mean significantly changed from $3.74 \pm 0.05 \mathrm{~mm}$ or $99.73 \pm 1.75$ $\mathrm{D}$ to $3.87 \pm 0.09 \mathrm{~mm}$ or $96.38 \pm 2.19 \mathrm{D}(p=0.0075)$ in PMMA group. Similarly, preoperative mean in MMA/EHA groups significantly changed from $3.63 \pm 0.04 \mathrm{~mm}$ or $102.75 \pm 1.15 \mathrm{D}$ to $3.74 \pm 0.05 \mathrm{~mm}$ or $99.73 \pm 1.35 \mathrm{D}(p=0.0391)$ in MMA/EHA 95:5 group, and from $3.59 \pm 0.03 \mathrm{~mm}$ or $103.90 \pm 0.87 \mathrm{D}$ to $3.78 \pm 0.05 \mathrm{~mm}$ or $98.67 \pm 1.33 \mathrm{D}(p=0.0004)$ in MMA/EHA $90: 10$ group. Peripheral radii of curvature were not collected due to difficulties in obtaining peripheral measurements. In some cases where it was possible to measure them, a peripheral flattening was also observed preserving its asphericity (e.g. peripheral radii of curvature changed from $3.79 \mathrm{~mm}$ to $3.83 \mathrm{~mm}$ after 90 days of implanting a PMMA intracorneal ring, and changed from $3.70 \mathrm{~mm}$ to $3.76 \mathrm{~mm}$ after 90 days of implanting a MMA/EHA 90:10).

Changes of refractive state throughout the experience are shown in Table 4. Before intracorneal rings implantation, all the hens exhibited moderate hyperopic errors. The preoperative mean refractive error was $3.64 \pm 0.59 \mathrm{D}$, ranging from +2.38 to +5.20 . The intracorneal ring procedures produced a significant difference in post-operative refractive state in PMMA and MMA/EHA groups compared with preoperative values. At the last follow-up, PMMA group presented an average of $2.52 \pm 0.85 \mathrm{D}(p=0.0008)$ more hyperopic than its preoperative magnitude. MMA/EHA groups also showed a significant change, MMA/EHA 95:5 group of 2.04 $\pm 0.7 \mathrm{D}$

Table 2

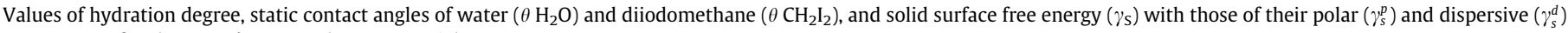
components for the MMA/EHA copolymer materials.

\begin{tabular}{|c|c|c|c|c|c|c|}
\hline Material & $\mathrm{H}(\%)$ & $\theta\left(\mathrm{H}_{2} \mathrm{O}\right)$ & $\theta\left(\mathrm{I}_{2} \mathrm{CH}_{2}\right)$ & $\gamma_{\mathrm{s}}\left(\mathrm{mN} \mathrm{m}^{-1}\right)[$ corr. $]$ & $\gamma_{s}^{d}\left(\mathrm{mN} \mathrm{m}^{-1}\right)$ & $\gamma_{s}^{p}\left(\mathrm{mN} \mathrm{m}^{-1}\right)$ \\
\hline PMMA & $1.07 \pm 0.072$ & $74.1 \pm 0.9$ & $40.5 \pm 1.4$ & 45.2 [99.8] & 39.5 & 5.7 \\
\hline MMA-EHA 95:5 & $1.00 \pm 0.034$ & $75.0 \pm 0.7$ & $42.8 \pm 1.4$ & 43.7 [99.6] & 38.2 & 5.5 \\
\hline MMA-EHA 90:10 & $0.84 \pm 0.017$ & $75.6 \pm 1.0$ & $40.5 \pm 0.4$ & 44.9 [99.7] & 39.4 & 5.5 \\
\hline MMA-EHA 85:15 & $0.79 \pm 0.031$ & $79.0 \pm 1.3$ & $39.2 \pm 1.4$ & 43.7 [99.5] & 40.0 & 3.7 \\
\hline PEHA $^{19}$ & - & 90 & 63 & 31.0 & 28.0 & 4.4 \\
\hline
\end{tabular}




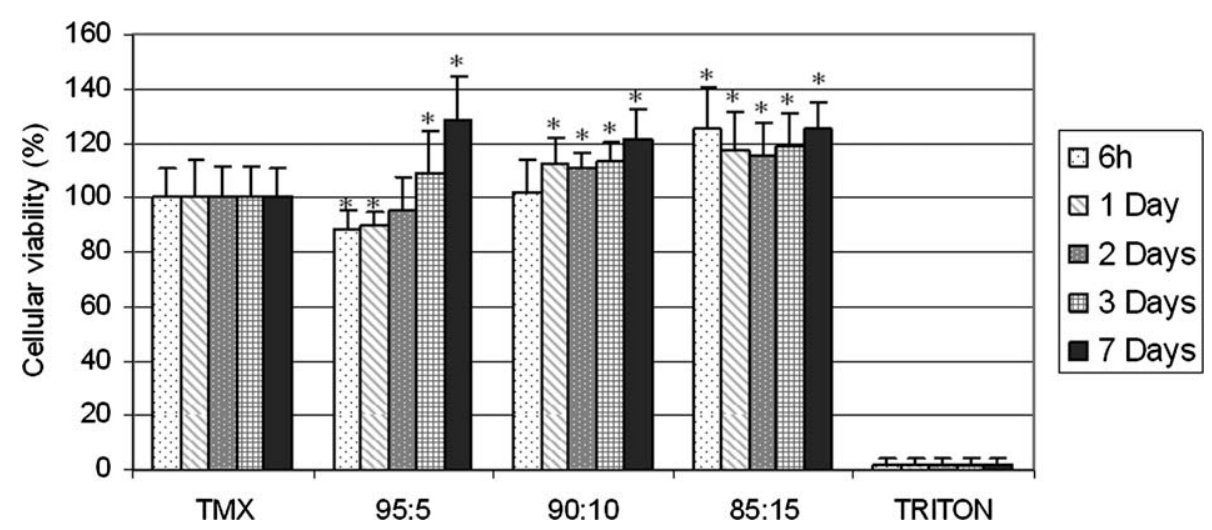

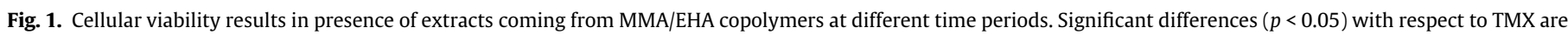
indicated by an asterisk $\left({ }^{*}\right)$ in the graph.

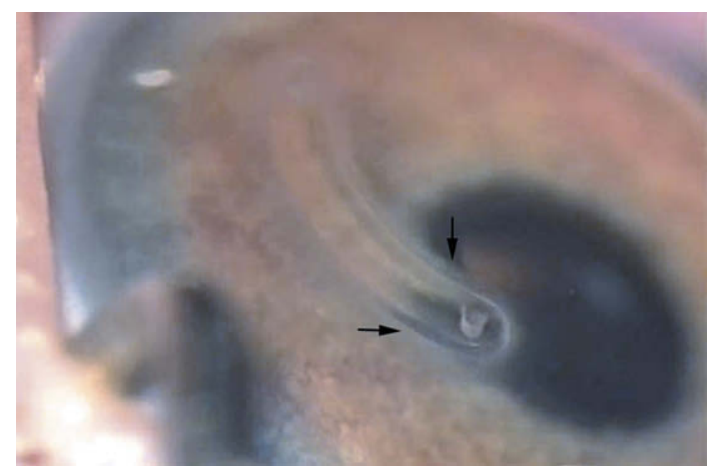

Fig. 2. Example of clinical course photograph from hen corneas after intracorneal ring implantation showing peri-annelar deposits (MMA/EHA 90:10). Magnification $7.7 \times$.

Table 3

Corneal radius of curvature (mean $\pm \mathrm{SD}, \mathrm{mm}$ ) at different periods of time.

\begin{tabular}{lllll}
\hline $\begin{array}{l}\text { Groups/ } \\
\text { treatment }\end{array}$ & $\begin{array}{l}\text { Sample } \\
\text { number }(n)\end{array}$ & Pre-op & Post (30 days) & Post (90 days) \\
\hline PMMA & 6 & $3.74 \pm 0.05$ & $3.88 \pm 0.10$ & $3.87 \pm 0.09$ \\
MMA-EHA 95:5 & 6 & $3.63 \pm 0.04$ & $3.74 \pm 0.07$ & $3.74 \pm 0.05$ \\
MMA-EHA 90:10 & 6 & $3.59 \pm 0.03$ & $3.79 \pm 0.03$ & $3.78 \pm 0.05$ \\
\hline
\end{tabular}

Table 4

Refractive state (mean $\pm S D$, D) at different periods of time.

\begin{tabular}{llll}
\hline $\begin{array}{l}\text { Groups/ } \\
\text { treatment }\end{array}$ & Pre-op & Post (30 days) & Post (90 days) \\
\hline PMMA & $3.82 \pm 0.51(n=12)$ & $6.49 \pm 1.35(n=12)$ & $6.37 \pm 0.78(n=6)$ \\
MMA-EHA & $3.28 \pm 0.58(n=6)$ & $4.10 \pm 1.06(n=6)$ & $5.32 \pm 0.59(n=6)$ \\
95:5 & & & \\
MMA-EHA & $3.60 \pm 0.68(n=6)$ & $5.39 \pm 1.15(n=6)$ & $6.80 \pm 0.99(n=6)$ \\
90:10 & & & \\
\hline
\end{tabular}

( $p=0.0008)$, and MMA/EHA $90: 10$ group of $3.20 \pm 1.43$ D $(p=0.0028)$ more hyperopic than its preoperative value.

The difference between preoperative optical measurements (corneal radii of curvature and refractive state) and the post-operative ones at 90 days was significantly higher for MMA/EHA 90:10 than for the PMMA or MMA/EHA 95:5.

\subsubsection{Direct transmittance}

The mean values of direct transmittance were similar in both groups, PMMA and MMA/EHA. PMMA presented values of direct transmittance of $89.23 \pm 5.20$ and $96.69 \pm 2.67$ at 30 and 90 days respectively. In MMA/EHA groups, direct transmittance values were of $93.47 \pm 2.50$ and $95.97 \pm 1.69$ in MMA/EHA $95: 5$ and $94.48 \pm 2.38$ and $94.97 \pm 2.61$ in MMA/EHA $90: 10$ at 30 and 90 days respectively.

\subsubsection{Histological findings after intracorneal ring implantation}

Conventional histology showed a triangular shaped channel where the ring was located. This triangle had sharp angles in PMMA intracorneal rings and blunt angles in those of MMA/EHA. Epithelial hypoplasia was observed over the segment in each sample. Descemet's membrane and endothelium appeared without change, and no breaks in the Bowman layer were observed. In both cases, we had not observed inflammatory cells around the channel, foreign-body granulomas or neovascularization.

In the lateral edges of the ring, a region of increased cellular density was noted in both groups, PMMA and MMA/EHA (95:5 and 90:10); in this region the samples stained positively with $\alpha$ SMA, indicating the presence of myofibroblasts. This hypercellularity decreased in the lateral edges of the segment and there were some SMA-positive cells at 90 days. In the PMMA group, a decrease of cells over the segment in the anterior stroma was observed. In addition, the myofibroblast and cellular distribution in the lateral edges of the segment made the rings turn in clockwise direction. However, in the MMA/EHA groups, cellular variation in the anterior stroma was observed in a lesser extension and practically there was no rotation of the segment (Figs. 3 and 4).

\section{Discussion}

Intracorneal ring segments which were proposed originally for the correction of low degrees of myopia [24] have been recently investigated as an additive surgical procedure to treat patients with ectatic corneal diseases $[3,4,13]$. This additive method presents the advantages of being a safe, efficient and reversible surgery [25-27]. Various types of intracorneal rings and implants made from different materials (e.g., PMMA and hydrogels) have been investigated to test their biocompatibility [10,28,29]. Currently, intracorneal ring segments are manufactured from PMMA, since different in vivo biocompatibility studies have showed a low rejection rate and acceptable predictability $[11,30]$. However, other studies described intrastromal deposits in the lamellar channel around the ring [14,31] and a decrease of the keratocyte density above and below the ring [15] as common clinical and histological findings, respectively. Also, anterior stromal aseptic necrosis, infiltrative keratitis or stromal thinning was reported [32-34]. Likewise, the pressure generated inside the stroma after 

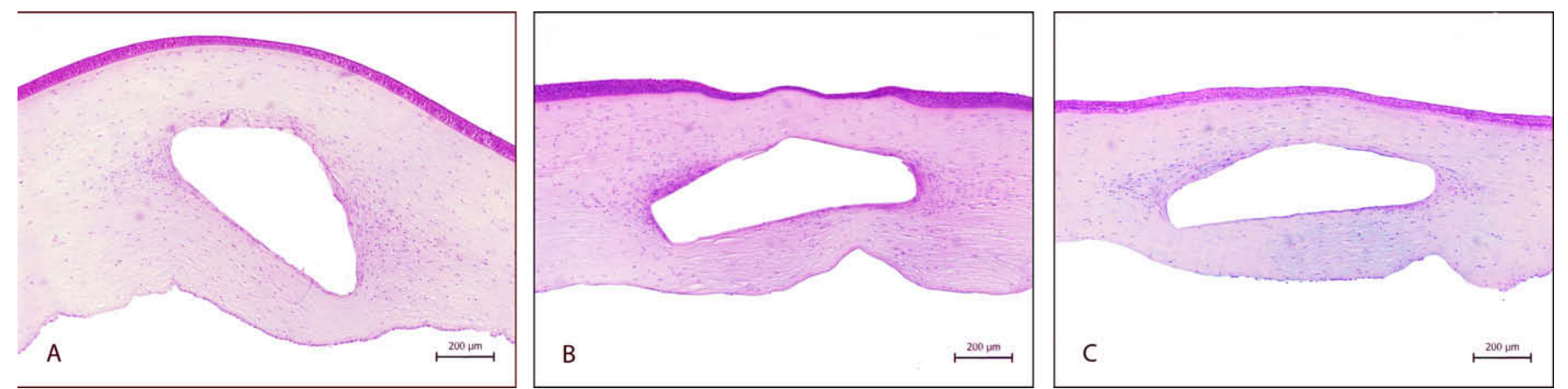

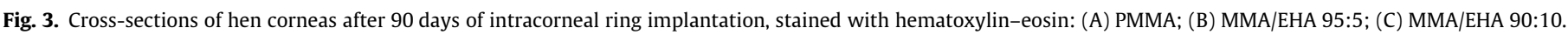
Magnification $100 \times$.

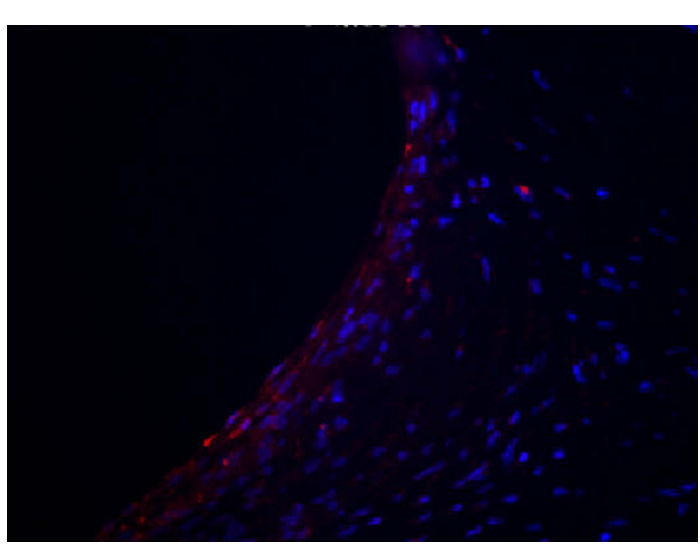

Fig. 4. Immunolocalization of $\alpha$-SMA (red) and DAPI (blue) in hen corneas after 90 days of PMMA intracorneal ring implantation. Magnification $400 \times$.

the PMMA ring implantation may move the segment in direction to the incision propitiating its rotation, migration or extrusion [13]. Therefore, the search for more flexible and permeable materials might improve the biocompatibility and tolerance of these segments. The approach of this work has been the preparation of materials of varying flexibility to overcome the problems associated with the rigidity of the PMMA segments. Thus, acrylic copolymers of MMA with controlled proportions of an acrylate having a long side chain, e.g. 2-ethylhexyl acrylate, were obtained by bulk reaction. Copolymer composition analysis showed contents of EHA lower than $15 \mathrm{wt} . \%$, and in all cases, composition of the copolymer approached that of the feed due to the high conversion reaction. The microstructure of copolymers depends on the values of reactivity ratios of the monomeric species. It is known that in the copolymerization of $n$-alkyl acrylates (e.g. $n=4-18$ ) with methyl methacrylate, the reactivity of the acrylate is one order of magnitude lower than that of the methacrylate $[35,36]$. The difference in the reactivities of the monomeric species has important effects mainly on the distribution of comonomeric sequences along the macromolecular chains. There is an exponential increase of the concentration of acrylate homotriads with the content of acrylate in the copolymer and the effect is cumulative as the conversion of monomers to copolymer chains increases [37]. Taking into consideration that copolymers prepared in this work contain proportions of the acrylate inferior to $15 \mathrm{wt} . \%$, the 2-ethylhexyl acrylate units will be predominantly distributed in acrylate centred hetero or alternating triads, giving materials with a microstructure consisting of a homogeneous distribution of the comonomeric units more than to the segregation of the acrylate units in microdomains. The purity of the copolymers was analysed by NMR spectroscopy, showing contents of residual monomers in the order of 1 wt.\% which are within the limit admitted for intracorneal ring segments $[38,39]$. In fact, when the copolymers were immersed in culture medium, and the extracts lixiviated to the medium were added to cell cultures, the cellular viability observed in the presence of extracts of copolymers was even higher than that observed in the presence of extracts of the control, indicating that no cytotoxic residues for the cells were eluted from the materials.

The determination of the glass transition temperature $\left(T_{\mathrm{g}}\right)$ of a polymer or copolymer provides accurate information about the relative flexibility of the system. PMMA is a rather rigid material with a $T_{\mathrm{g}}$ of $110^{\circ} \mathrm{C}$ whereas poly(2-ethylhexyl acrylate) (PEHA) is a soft material with a $T_{\mathrm{g}}$ as low as $-50^{\circ} \mathrm{C}$ [40]; what this means is that at ambient temperature, the PEHA presents characteristics similar to those of rubbers. The $T_{\mathrm{g}}$ values of the MMA/EHA copolymers were between those of homopolymers. Moreover, a linear decrease of $T_{\mathrm{g}}$ with the weight fraction of EHA in the copolymer was observed $(R=0.994)$, indicating an additive contribution of both comonomeric units in the copolymer. Flexibility of the copolymeric materials was manifested mainly in copolymers containing 10-15 wt.\% EHA, for which the $T_{\mathrm{g}}$ lowered in approximately $30-40{ }^{\circ} \mathrm{C}$ with respect to pristine PMMA. Stiffness of PMMA Ferrara rings is considered to be the cause of some biological complications. Stiffness of the copolymers was analysed through microhardness $\left(H_{\mathrm{v}}\right)$ measurements, and results indicated that all copolymers were less rigid than PMMA, showing a linear decreasing pattern with the content of acrylate $(R=0.990)$. Also in this parameter, the improved flexibility was apparent for copolymers containing 10-15 wt.\% EHA, which presented values of $H_{\mathrm{v}}$ approximately 30-50 MPa lower than that of PMMA. Moreover, it was found that the copolymer with $10 \mathrm{wt}$.\% EHA possessed a microhardness similar to that of the dehydrated cornea of gallus domesticus analysed under the same conditions, which means that this copolymer seems to be the most appropriate to substitute PMMA and therefore to be tested in further experiments.

Wettability is important in the interactions of the material with the biological medium. Wettability of the copolymeric materials slightly decreased with the presence of the predominantly hydrophobic 2-ethylhexyl acrylate unit; however, it was little affected with respect to that of PMMA, due to the low proportions of EHA in the copolymers. Hydration degree of the copolymers richer in EHA was around $0.8 \%$, that is, in the order of that presented in commercial intracorneal ring devices. Water contact angle of the copolymers increased up to $79^{\circ}$ but in all cases remained lower than values reported for MMA/EHA copolymers of 40/60 to 60/ $40 \mathrm{M}$ ratios, which presented angles around $90^{\circ}$ [41], very close to that of the homopolymer [42]. Values of surface energy of solid for copolymers hardly changed with respect to that of PMMA, and they were higher than $31.0 \mathrm{mN} \mathrm{m}^{-1}$ reported for PEHA [40], indicating scarce hydrophobic modification on the surface of the 
materials. Refractive index was measured in the hydrated discs as an approximation to the in vivo situation. Values for copolymers containing 5-10 wt.\% EHA did not change with respect to PMMA, and a slight decrease was measured for the copolymer containing 15 wt.\% EHA.

Then, if we take into consideration the overall properties of the copolymeric materials, it is obvious that their main feature is the lower stiffness without impairing or hardly modifying the rest of the properties compared to PMMA. Thus, for the study of the in vivo biocompatibility the MMA/EHA 95:5 and 90:10 copolymers were selected based on the fact that in both compositions, rigidity diminished appreciably and even became equal to that of animal dehydrated corneas for the copolymer 90:10. Thus, experiments were performed by the implantation of the different acrylic intracorneal ring segments and the clinical outcomes and histological effects were evaluated to determine whether the MMA/EHA copolymers might be considered as an alternative for intracorneal rings. The final period of time was 90 days because the curve of visual recovery and refractional stabilization takes at least three months in average [30].

Previous studies have explored the effects of intracorneal ring segments on a variety of alternative animal models, selecting rabbits as the animal more suitable for evaluating the safety of the intracorneal rings effects $[14,24,43]$. However, in this study we chose the hen as the experimental animal since, histologically, its cornea resembles human cornea in size and structure: it is thinnest centrally and it thickens toward the periphery. Furthermore, the proportions of hen cornea layer [44,45] and the fibrillar collagen arrangement $[46,47]$ are very similar to those of human cornea. Also, in previous experiments the hen was used as animal model to study the wound-healing response after intracorneal ring segment implantation by our group, so that the learning curve was already realized [48].

The intracorneal ring acts as tissue addition, leading to a flattening in the corneal surface [6] by an arc-shortening effect of the corneal lamellae $[8,9]$. In this study, intracorneal ring segment implantation did result in flattening of the cornea and in a significant change in refractive error in both groups, PMMA and MMA/ EHA. The results for the copolymers showed a decrease in the mean average keratometric values, indicating that the central curvature values were significantly flattened after three months compared to the preoperative baseline values. A significant postoperative change in the refractive state, without regression or lost of the refractive effect, was also observed at the last follow-up. These data compared well with previous human reports $[4,27,30]$. In this aspect, the MMA/EHA 90:10 copolymer had greater effect than PMMA or MMA/EHA 95:5 copolymer.

Intracorneal ring segments implantation is associated with a range of complications. The major complication reported was segment migration and extrusion; however, we did not observe the high incidence of ring extrusion, in $19.6 \%$ of the eyes, as reported by Kwitko and Severo [13]. The immediate response to intracorneal ring segment involved a localized edema and corneal haze in the incision and channel where the segments were placed, and they disappeared in most cases over time. Approximately between 7 and 30 days after implantation, peri-annelar deposits regularly appear along the inner and outer curvature of the intracorneal ring segments and continue at 90 days in the majority of the eyes [12]. Like humans, most of the hen corneas developed these deposits. The question whether the occurrence of the deposits can be reduced remains unclear.

Corneal tolerance of the different groups was analysed through conventional histology. The wound-healing response around the channel after PMMA rings in this animal model was previously described [48]. Histologically, several findings underline the biocompatibility of both groups, since there was no evidence of an inflammatory response at 30 and 90 days. All the samples showed hypoplasia of the epithelium over the segments and an increased keratocyte density at the edges of the rings, these findings being in agreement with previous works [14,15]. Several studies reported that the deposits observed on biomicroscopic examination consist of intracellular lipid accumulations and new collagen formation. These deposits were observed in the edges of the segment where increased cell density was present, being a connection between the deposits and the keratocyte activation stimulated by the wound-healing response [14]. The presence of myofibroblast in this zone suggested an active wound-healing process. However, we did not identify lipid deposits since cryopreservation was not performed.

Samini et al. reported [15] a decrease in keratocyte density above and below the segment. In the PMMA group a decrease of keratocyte density was detected in the anterior stroma over the implant; however, this finding was detected in a lesser degree in the MMA/EHA groups. Comparing the MMA/EHA groups with that of PMMA, we observed how in the former groups the edges of the segments presented a more curved surface than that observed with PMMA. This effect might result in the compression forces in the stromal lamellae being distributed throughout a larger stromal surface, causing less amount of physiological stress and triggering lower rotation of the segment. We suggest that this effect can derive from the higher flexibility of the MMA/EHA copolymers compared to PMMA, reflecting an improved in vivo response and allowing a better adaptation.

\section{Conclusions}

The biophysical measurements performed in this study and the histological results obtained with PMMA and MMA/EHA copolymers intracorneal ring segments demonstrate a better in vivo response after the implantation of the MMA/EHA 90:10 copolymer, and this was attributed to the higher flexibility of this material. This material might be considered suitable as an alternative for application in clinical practice. Long-term follow-up studies are currently in progress to observe whether this copolymer provides a permanent flattening effect and to analyse its biocompatibility in the corneal stroma. Initial results of the MMA/EHA copolymer segments seem to be very promising.

\section{Acknowledgement}

This research was supported by Spanish Ministry of Science and Innovation (PROFIT CIT-300100-2007-50).

\section{Appendix A. Figures with essential colour discrimination}

Certain figures in this article, particularly Figures 2, 3, and 4, are difficult to interpret in black and white. The full colour images can be found in the on-line version, at doi:10.1016/ j.actbio.2010.01.014.

\section{References}

[1] Rabinowitz YS. Keratoconus. Surv Ophthalmol 1998;42:297-319.

[2] Binder PS. Ectasia after laser in situ keratomileusis. J Cataract Refract Surg 2003;29:2419-29.

[3] Colin J, Cochener B, Savary G, Malet F. Correcting keratoconus with intrastromal rings. J Cataract Refract Surg 2000;26:1117-22.

[4] Siganos D, Ferrara P, Chatzinikolas K, Bessis N, Papastergiou G. Ferrara intrastromal rings for the correction of keratoconus. J Cataract Refract Surg 2002;28:1947-51.

[5] Alio JL, Salem TF, Artola A, Osman AA. Intracorneal rings to correct corneal ectasia after laser in situ keratomileusis. J Cataract Refract Surg 2002;28:1568-74. 
[6] Barraquer JL. Modification of refraction by means of intracorneal inclusion. Int Ophthalmol Clin 1966;6:53-78.

[7] Blavatskaya ED. Intralamellar homoplasty for the purpose of relaxation of refraction of the eye. Arch Soc Am Ophthalmol Optom 1968;6:311-25.

[8] Burris TE, Baker PC, Ayer CT, Loomas BE, Mathis L, Silvestrini T. Flattening of central corneal curvature with intrastromal corneal ring of increasing thickness: an eye bank eye study. J Cataract Refract Surg 1993;19(Suppl):182-7.

[9] Burris TE, Holmes Higgin DK, Silvestrini TA, Scholl JA, Proudfoot RA, Baker PC Corneal asphericity in eye bank eyes implanted with the intrastromal corneal ring. J Refract Surg 1997;13:556-67.

[10] D'Hermies F, Hartmann C, Von Ey F. Biocompatibility of a refractive intracorneal PMMA ring. Fortschr der Ophthalmol 1991;88:790-3.

[11] Nosé W, Neves RA, Burris TE, Schanzlin DJ, Belfort Jr R. Intrastromal corneal ring: 12 months sighted myopic eyes. J Refract Surg 1996;12:20-8.

[12] Ruckhofer J, Twa MD, Schanzlin DJ. Clinical characteristics of lamellar channel deposits after implantation of INTACS. J Cataract Refract Surg 2000;26:1473-9.

[13] Kwitko S, Severo NS. Ferrara intracorneal ring segments for keratoconus. J Cataract Refract Surg 2004;30:812-20.

[14] Twa MD, Ruckhofer J, Kash RL, Costello M, Schanzlin DJ. Histologic evaluation of corneal stroma in rabbits after intrastromal corneal ring implantation. Cornea 2003;22:146-52.

[15] Samini S, François Leger F, Touboul D, Colin J. Histopathological findings after intracorneal ring segments $\left(\right.$ INTACS $\left.^{\circledR}\right)$ implantation in keratoconic human corneas. J Cataract Refract Surg 2007;33:247-53.

[16] Fowkes FM. Predicting attractive forces at interfaces. Ind Eng Chem 1964:56:40-53.

[17] Owens DK, Wendt RC. Estimation of the surface free energy of polymers. J Appl Polym Sci 1969;13:1741-7.

[18] Ferrara de A Cunha P. Técnica cirúrhica para correçao de miopía; anel corneano intra-estromal. Ver Brás Oftalmol 1995;54:577-88.

[19] Schaeffel F, Howland HC. Corneal accommodation in chick and pigeon. J Comp Physiol Sensory A Sen Neural Behav Physiol 1987;160:375-84.

[20] Garcia de la Cera E, Rodriguez G, de Castro A, Merayo J, Marcos S Emmetropization and optical aberrations in a myopic corneal refractive surgery chick model. Vision Res 2007;47:2465-72.

[21] Choh V, Sivak JG. Lenticular accommodation in relation to ametropia: the chick model. J Vision 2005;5:165-76.

[22] Li T, Trolio D, Glasser A, Howland HC. Constant light produces severe corneal flattening and hyperopia in chickens. Vision Res 1995;35:1203-9.

[23] Mar S, Martínez-García MC, Blanco JT, Torres RM, González VR, Nájera S, et al Transmittance and scattering during wound healing after refractive surgery keratomileusis in hens. Proc SPIE 2004;5622:56-61.

[24] Flemming JF, Reynolds AE, Kilmer L, Burris TE, Abbott RL, Schanzlin DJ. The intrastromal corneal ring: two cases in rabbits. J Refract Surg 1987;6:227-32.

[25] Burris TE. Intrastromal corneal ring technology: results and indications. Curr Opin Ophthalmol 1998;9:9-14.

[26] Asbell PA, Uçakhan ÖÖ, Durrie DS, Lindstrom RL. Adjustability of refractive effect for corneal ring segments. J Refract Surg 1999;15:627-31.

[27] Alió JL, Shabayek MH, Artola A. Intracorneal ring segments for keratoconus correction: long-term follow-up. J Cataract Refract Surg 2006;32:978-85

[28] Rodrigues MM, McCarey BE, Waring 3rd GO, Hidayat AA, Kruth HS. Lipid deposits posterior to impermeable intracorneal lenses in rhesus monkeys: clinical, histochemical, and ultrastructural studies. Refract Corneal Surg 1990;6:32-7.

[29] Parks RA, McCarey BE, Knight PM, Storie BR. Intrastromal crystalline deposits following hydrogel keratophakia in monkeys. Cornea 1993;12:29-34.

[30] Schanzlin DJ, Abbott RL, Asbell PA, Assil KK, Burris TE, Durrie DS, et al. Twoyear outcomes of intrastromal corneal ring segments for the correction of myopia. Ophthalmology 2001;108:1688-94.

[31] Twa MD, Kash RL, Costello M, Schanzlin DJ. Morphologic characteristics of lamellar channel deposits in the human eye: a case report. Cornea 2004;23:412-20.
[32] Bourges JL, Trong TT, Ellies P, Briat B, Renard G. Intrastromal corneal ring segments and corneal anterior stromal necrosis. J Cataract Refract Surg 2003;29:1228-30.

[33] McAlister JC, Ardjomand N, Ilari L, Mengher LS, Gartry DS. Keratitis after intracorneal ring segment insertion for keratoconus. J Cataract Refract Surg 2006;32:676-8.

[34] Ruckhofer J, Stoiber J, Alzer E, Grabner G. One year results of European multicenter study of intrastromal corneal ring segments. Part 2: complications, visual symptoms, and patient satisfaction; the Multicenter European Corneal Correction Assessment Study Group. J Cataract Refract Surg 2001;27:287-96.

[35] Brosse JC, Gauthier JM, Lenain JC. Synthesis of polymers with hydroxyl end groups by radical reactions. 11 . Study of the copolymerization of methyl methacrylate with various acrylates and methacrylates. Determination of reactivity ratios. Makromol Chem - Macromol Chem Phys 1983;184:505-17.

[36] Jordan EF, Bennett R, Shuman AC, Wrigley AN. Reactivity ratios and copolymerization parameters for copolymers incorporating normal octadecyl acrylate and n-normal octadecylacrylamide. J Polym Sci Part A-1 Polym Chem 1970;8:3113-21.

[37] Goñi I, Gurruchaga M, Vázquez B, Valero M, Guzmán GM, San Román J. Graft copolymerization of ethyl acrylate with alkyl methacrylates onto amylose initiated by cerium(IV). Microstructure of graft copolymers with respect to statistical copolymers. Polymer 1994;35:1535-41.

[38] Leibowitz HM, Trinkaus-Randall V, Tsuk AG, Franzblau C. Progress in the development of a synthetic cornea. Progress in Retinal and Eye Research 1994;13:605-21.

[39] Chirila TV, Barret GD, Russo AV, Constable IJ, van Saarloos PP. Laser-induced damage to transparent polymers: chemical effect of short-pulsed (Q-switched) Nd:YAG laser radiation on ophthalmic acrylic biomaterials. II. Study of monomer release from artificial intraocular lenses. Biomaterials 1990;11:313-20.

[40] Wise DL, Trantolo DJ, Altobelli DE, Yaszemski MJ, Gresser JD, Schwartz ER, editors. Encyclopaedic handbook of biomaterials and bioengineering. New York, Basel, Hong Kong: Marcel Dekker, Inc.; 1995.

[41] Lospa C, Rusu M, Voué M, Adao MH, Suckling P, De Coninck J. Optical and surface properties of acrylic copolymers for crystalline lens implants. J Optoelectron Adv Mater 2005;7:2831-4.

[42] Vázquez B, San Román J, Peniche C, Cohen ME. Polymeric hydrogels with flexible hydrophobic chains. Control of the hydration and interactions with water molecules. Macromolecules 1997;30:8440-6.

[43] Hartmann C, Rieck PW, Holzkämper C, Pouliquen Y, Renard G. The intrastromal corneal ring in clinical refractive surgery: reference to results in rabbit eyes. Graefés Arch Clin Exp Ophthalmol 2000;238:465-71.

[44] Fowler WC, Chang DH, Roberts BC, Zarovnaya EL, Proia AD. A new paradigm for corneal wound healing research: the white leghorn chicken (Gallus gallus domesticus). Curr Eye Res 2004;28:241-50.

[45] Martinez-Garcia MC, Merayo-Lloves J, Blanco-Mezquita T, Mar-Sardaña S. Wound healing following refractive surgery in hens. Exp Eye Res 2006;83:728-35.

[46] Boote C, Hayes S, Jones S, Quantock AJ, Hocking PM, Inglehearn CF, et al. Collagen organization in the chicken cornea and structural alterations in the retinopathy, globe enlarged (rge) phenotype - an X-ray diffraction study. J Struct Biol 2008;161:1-8.

[47] Hayes S, Boote C, Lewis J, Sheppard J, Abahussin M, Quantock AJ, et al. Comparative study of fibrillar collagen arrangement in the corneas of primates and other mammals. Anat Rec (Hoboken) 2007;290:1542-50.

[48] Merayo-Lloves J, Blanco-Mezquita T, Ibares-Frias L, Fabiani L, Álvarez-Barcia A, Martínez-García C. Induction of controlled wound healing with PMMA segments in the deep stroma in corneas of hens. Eur J Ophthalmol 2010;20:62-70. 